\title{
La comunidad cristiana de Mārida durante el periodo andalusí *
}

\author{
The christian community of Mārida in the andalusi period
}

\author{
Bruno Franco MORENO **
}

\begin{abstract}
RESUMEN
La comunidad cristiana de Mérida tras la presencia islámica del 713 d.C./94 H. permanecerá ajena en un principio a las luchas intestinas que se desarrollan en alAndalus hasta la proclamación del emirato con 'Abd al-Raḥmān I. Será al finalizar el siglo VIII e inicios del IX, cuando la Iglesia de Mārida participe activamente en los sucesos que se desarrollan en la ciudad en su lucha contra el poder cordobés, que terminará con la extinción de la sede emeritense en los albores de la décima centuria. Después de un minucioso estudio de los textos se puede afirmar que no hubo traslado de sede a Badajoz en el siglo X, como cierta historiografía ha mantenido, confirmándose que fue una manipulación tardía (s. XIII) para servir a los intereses de la monarquía y de la iglesia. El trabajo arqueológico

desarrollado en los últimos años en la ciudad y en el medio rural ha venido a confirmar lo recogido en los textos escritos.
\end{abstract}

\section{PALABRAS CLAVE}

Comunidad cristiana, Mérida, Omeyas, alAndalus, fuentes historiográficas, registro material.

\section{ABSTRACT}

After the Islamic conquest in 713 A.D./94 Hegira, the Christian community in Merida remained unscathed by infighting that took place in al-Andalus until the proclamation of the Emirate by 'Abd al-Rahmmān I. Only at the end of the eighth and early ninth centuries will the Church of Mārida actively participate in the fighting that took place in the city against the authorities in Cordova, ending with the extinction of the Meridan See at the beginning of the tenth century. After a detailed study of the texts, we can conclude there was no transfer of the See to Badajoz in the tenth century, as some historians have maintained, confirming that it was a late documentary manipulation (from the thirteenth century) that took place to serve the interests of the monarchy and of the Church.

Archaeological work in recent years in the city and in the surrounding rural areas has also corroborated what the written sources contain.

\section{KEY WORDS}

Christian community, Merida, Umayyad dynasty, al-Andalus, historical sources, archaeological evidence.

\footnotetext{
* Fecha de recepción del artículo: 2012-12-11. Fecha de aceptación del artículo: 2013-1-28.

* Consorcio de la Ciudad Monumental histórico-artística y arqueológica de Mérida. Grupo de investigación -Hum0024- Dirección Gral. de Modernización e Innovación Tecnológica de la Junta de Extremadura. C.e.: bruno@consorciomerida.org.
} 


\section{INTRODUCCIÓN}

Con posterioridad a la capitulación de la ciudad a las tropas encabezadas por el walī de Ifriquīya, Mūsà ibn Nușāyr el 30 de junio del 713 d.C./ 94 H., no volvemos a tener noticias que hagan una referencia expresa a la Comunidad cristiana de la ciudad o a su metrópolis hasta la primera mitad del siglo IX. Las fuentes historiográficas únicamente recogen acontecimientos de las luchas y rivalidades existentes entre árabes (baladíes, yemeníes y qasyes) contra las distintas tribus bereberes asentadas en la ciudad o su territorio), de las que resaltamos las más significativas:

«Reunidos los bereberes de Galicia, Astorga, Mérida, Coria y Talavera, eligieron por jefe a Ibn ... y con un ejercito innumerable pasaron el Tajo (con seguridad por el vado de Alconétar) en busca de Malik ibn Qațan, que mandó contra ellos a sus dos hijos, Qațan y Umayya, con los sirios compañeros de Balŷ y los baladíes (los del país: primeros árabes que se asentarosn en al-Andalus)...»... Balŷ se hace con el poder y «los dos hijos de Ibn Qațan huyeron uno a Mérida y otro a Zaragoza, donde permanecieron algunos días concertando su plan»1.

«el asedio a que fue sometido Ta'alaba ibn Salama en Mérida, por baladíes, árabes y bereberes, quienes no dudaron de su victoria» ${ }^{2}$. En la obra mencionada se especifica que "salió, sin embargo, y combatió valerosamente; más no alcanzó ventaja ninguna, y tuvo que encerrarse en la ciudad de Mérida, y mandar un emisario al lugarteniente que había dejado en Córdoba, para que fuese a él con las tropas que allí quedaban, a fin de combatir a la gente del país. Estando de esta suerte, cercado en Mérida por la gente del país y los bereberes, pues éstos eran los más numerosos, llegó la fiesta del Fițr o Aḍhà (del cordero), y como observase Táalaba que se descuidaban y diseminaban, hizo una salida al amanecer del día de la fiesta, los derrotó con gran matanza y redujo a cautiverio sus mujeres e hijos, cosa que ni el mismo Balŷ se había atrevido a hacer...»33.

Con posterioridad a los sucesos mencionados, ya en el gobierno de Yūsuf alFihrī, tiene lugar la entrada en al-Andalus de 'Abd al-Raḥmān ibn Mu'āwiya, que dará lugar a una serie de enfrentamientos donde la población de Mérida jugará un papel importante, en este caso a favor del gobernador «oficial». Según recoge la crónica del 'Ajbār Maŷmū'a, gran parte de su familia se encontraba residiendo en la antigua capital de la Lusitania4:

"Viendo Yūsuf que los distritos militares no le secundaban, escribió a los beledíes y a los de Mérida y Fuente de Cantos, los cuales les accedieron. Allí se

\footnotetext{
1 'AJBĀR MAŶYMŪ'A, Lafuente y Alcántara (en sucesivos: 'Ajbār Maŷmūa) con introd. y traducción. Colección de obras arábigas de Historia y Geografía, Madrid. 1876. reed. 1984, trad. págs. 48-50).

2 Hayyān, apud al-Maqqarī, Nafḥ al-tīb min gusn al-Andalus. Traducción parcial GAYANGOS, P., The history of the Mohammedan Dynasties in Spain, London, 1840-43, V, II, pág. 14.

3 'Ajbār Maŷmū'a, trad. págs. 53-54.

4 'Ajbār Maŷmūa'a, trad. pág. 91.
} 
encontraba la mayor parte de su familia....Yūsuf recibió cartas de ellos, en que le Ilamaban, y huyó de Córdoba a Mérida en el 141/759».

En este texto podemos constatar como el territorio dependiente jurídicamente de Mārida, seguía en gran medida contando con gran número de población baladí y bereber, los cuales se habrían asentado tras la entrega por capitulación de la ciudad, y en las sucesivas oleadas migratorias provenientes del norte de África. Sin que por ello nos olvidemos del gran número de población autóctona que en ella habitaba, pero que en este primer momento no participaba en los asuntos internos de los musulmanes.

Avanzando en este mismo texto, se vuelve a mencionar la gran aportación árabo-bereber proveniente de Mérida que combate a favor del gobernador Yūsuf al-Fihrī:

«Completo el ejército de Yūsuf, marchó contra el Merwani, y viendo que permanecía en Sevilla con pocos siriacos, tranquilo con respecto a aquel enemigo poco temible y poderoso, volvíose para salir al encuentro de Ibn Muawiya, con los árabes, bereberes y demás gente de Mérida y Fuente de Cantos y los que se le habían agregado de Sevilla, todos los cuales formaban un grueso ejército" 5 .

A lo largo del emirato de Hišām I, que se encontraba de gobernador en la ciudad de Mérida cuando recibió la noticia de la muerte de su padre el emir 'Abd alRaḥmān ibn Mu'awiyya, no volvemos a tener noticias de gran trascendencia para Mérida y su entorno, con excepción del asilo que vino a buscar Sulaymān, hermano del emir, que finalmente fue expulsado por el gobernador de la ciudad, de nombre Hudayr ${ }^{6}$. Será con los siguientes emires de al-Andalus, al-Hakam I, 'Abd al-Raḥmān II y Muhammad I, cuando se inicie en Mérida y en toda la Frontera Inferior una espiral de violencia contra los dictámenes emanados desde Córdoba?.

Estos acontecimientos traspasaron las fronteras de al-Andalus, como sabemos por una carta conservada que fue enviada por el emperador Ludovico Pío (colocada entre las de Eginardo) dirigida a la ciudad de Mérida, en la que exhortaba a mantenerse firmes ante el opresor musulmán ${ }^{8}$.

\ Hemos oido vuestra tribulación, y las muchas angustias que padeceis por la crueldad del Rey Abdiraman, el qual por la demasiada codicia con que quiere quitaros vuestros bienes, os ha afligido muchas veces con violencia, como tenemos noticia haberlo hecho tambien su padre Abolaz, el qual aumentado injusta-

\footnotetext{
5 Ajbār Maŷmū'a, trad. pág. 92.

6 IBN 'IDĀRII, Histoire de I'Afrique et de I 'Espagne (Al-Bayān al-mugrib) t. II, traduite et annotée par E. Fagnan, Alger, 1904, reed.1948, págs. 58-62.

7 Recogido por IBN HAYYĀN, al- Muqtabis, Crónica de los emires Alhakam I y Abdarrahmān I/ entre los años 796 y 847 (Al-Muqtabis II- I). Trad., notas e índices de Mạ̣mūd Alī Makkī y Federico Corriente, I.E.I.O.P., 2001.

${ }^{8}$ FLÓREZ, E: España Sagrada, T. XIII. De La Lusitania en común y de su metrópoli en particular, 2. ․ Edic. Madrid, 1816, Cap. IX, pág. 254.
} 
mente los tributos de que no erais deudores, y exigiendolos por fuerza; hacia de amigos enemigos, $y$ de obedientes contrarios, intentando quitaros la libertad, $y$ oprimiros con injustos tributos. Pero vosotros, según hemos oido, siempre como varones esforzados habeis rebatido con valor las injurias hechas por los Reyes malvados, y resistido á su crueldad y avaricia, segun al presente practicais, como nos asegura la relacion de muchos. Por tanto hemos tenido á bien escribiros esta Carta, consolandoos, y exhortandoos á que persevereis en defender a vuestra libertad contra un Rey tan cruel, y resistais, como hasta aqui, á su furor y crueldad. $Y$ por quanto no solo es vuestro enemigo, sino nuestro; peleemos contra su crueldad de comun consejo. Yo intento con la ayuda de Dios embiar en el proximo Verano mi Egercito á los limites de mi jurisdiccion, para que alli espere vuestro orden del tiempo de pasar adelante, si os parece bien, que en vuestra ayuda se ocupe contra el comun enemigo: de suerte, que si Abdiraman, ó su Egercito quisiere ir contra vosotros, lo impida mi tropa. Y os hago saber, que si quisiereis apartaros del, $y$ venir á mí, os concedo plenisimamente, que goceis vuestra antigua libertad, sin alguna diminucion, ni tributo: y no pretenderemos que vivais en otra ley mas que en aquella en que quisiereis vivir: ni nos portaremos con vosotros, sino como como con amigos y confederados honorificamente en defensa de nuestro reyno. Dios os guarde como deseamos'.

La pretensión del emperador carolingio era mantener abierto un segundo frente que distrajera a las fuerzas emirales, y de este modo alejar el peligro de la Frontera Superior, porque difícilmente un ejército foráneo podría alcanzar la ciudad de Mérida desde tan larga distancia.

Tras la construcción de la alcazaba para residencia de los obedientes al emir, después de dos décadas de levantamientos en la ciudad, y después de 30 años en los que las fuentes historiográficas no recogen ningún acontecimiento digno de mención con relación a Mérida, la única documentación que ha llegado hasta nuestros días en referencia a la comunidad cristiana de la ciudad es la aportada en la celebración de los concilios celebrados en Córdoba en los años 839, 852 y 862 , donde se recoge la participación del obispo Ariulfo, en el último por carta ${ }^{9}$. Por último citar al Muqtabis II/2 de Ibn Hayyān, que documenta dos nuevos ataques a la ciudad durante los años 866/252 y 868/254, éste último de transcendentales consecuencias para el futuro de la ciudad y sus moradores ${ }^{10}$. A partir de este momento el vacío documental es elocuente, sobre todo si tenemos en cuenta que desde el año 876/261 la ciudad será ocupada por la tribu bereber de los Banū Tayīt, que procedentes de la zona de Coria y Egitania, permanecerán independientes al poder emiral hasta su toma definitiva por al-Nașir en el 929/316 ${ }^{11}$. De la otrora comunidad cristiana de Mérida se pierde todo rastro textual y material a partir de este momento, no volviéndose a recuperar hasta después de la conquista de la ciudad por las tropas encabezadas por Alfonso IX en 1230.

\footnotetext{
9 SANSÓN, Abad, Apologético, Lib. II, praefatio, n.ํVIII. Edic. est. y trad. Palacios Royán, J. Madrid, 1998.

10 IBN HịYYĀN, Al-Muqtabis II-2. Ed. Maḥmūd 'Alī Makkī, El Cairo, 1994.

11 FRANCO MORENO, B. De Emerita a Mārida. El territorio (S. VII-X) Vol. I-II. EAE, Saarbrücken (Germany), 2011, págs. 57-65.
} 


\section{LA COMUNIDAD CRISTIANA DE MĀRIDA EN EL PERIODO OMEYA DE AL-ANDALUS}

Conocemos por la escasa producción historiográfica conservada, que había una amplia comunidad cristiana en al-Andalus: son los denominados «mozárabes», aunque esta terminología únicamente aparece en las fuentes a partir del s. XI, en referencia concreta a los que profesaban este credo en Toledo ${ }^{12}$. Pero algunos historiadores de finales del siglo XIX dieron preeminencia a esta denominación al referirse a los cristianos de épocas anteriores que vivieron en suelo andalusí o se establecieron allende el Duero ${ }^{13}$. Etimológicamente la denominación exacta proviene del vocablo árabe musta'rib/musta'riba (arabizado/os). Conocemos gracias a textos de naturaleza muy diversa (árabes y latinos), la existencia de algunos grupos y de comunidades cristianas en la sociedad islámica andalusí. Se conoce también su estatuto jurídico, por aplicación general del estatuto de los «protegidos» a cristianos y judíos, en la legislación musulmana, aunque la aplicación de estos textos legales no fue seguramente monolítica en todos los lugares y periodos de la historia musulmana. Tenemos pues, dos bases positivas y documentadas para conocer a los cristianos de al-Andalus: su existencia documentada y la legislación que fundamenta su estatuto social y regula sus actuaciones en la sociedad andalusíi ${ }^{14}$.

No obstante dentro de la sociedad andalusí eran denominados como nașrānīyyun (nazarenos), rum o rūmī (rumies o cristianos bizantinos), dimmiyūn o dumnīes (protegidos), mu'ahadun (población bajo pacto) y muśrik o politeísta, entre las acepciones más utilizadas ${ }^{15}$. Pero en esto como en otros muchos aspectos que tienen relación con conceptos o términos recogidos en los textos conservados, la acepción que ha triunfado en la historiografía ha sido el calificativo de mozárabes ${ }^{16}$. Nosotros opinamos que en todo el territorio dependiente de la Mérida andalusí de periodo omeya, existió una considerable comunidad cristiana tras

12 Esta terminología nunca aparece en las fuentes árabo-islámicas, encontrándose dicho término por primera vez, en un documento latino-leonés del primer tercio del siglo XI, el año 1026 para ser más exactos, en el que se habla de Muzárabes, en LAPIEDRA GUTIÉRREZ, E. Cómo los musulmanes llamaban a los cristianos hispánicos. Colección Textos Universitaris, Alicante, 1997, pág. 308, notas 577-578.

13 BANGO TORVISO, I. G. «Un gravísimo error en la historiografía española. El empleo equivocado del término mozárabe» en Simposio Internacional «El legado de al-Andalus. El arte andalusí en los reinos de León y Castilla durante la Edad Media», Fundación del Patrimonio Histórico de Castilla y León, Valladolid, 2007, págs. 75-88.

14 EPALZA, M. (de) «La Islamización de al-Andalus: Mozárabes y neomozárabes», Revista del Instituto Egipcio de Estudio Islámicos, XXIII, Madrid, 1985-86, págs. 171-179.

15 LAPIEDRA GUTIÉRREZ, E. Cómo los musulmanes llamaban a los cristianos hispánicos. Colección Textos Universitaris, Alicante, 1997.

16 RICHARD HITCHCOCK, uno de los autores más respetados y autorizados en el uso de «mozárabe», reconoce que se ha convertido en un término genérico aplicable a cualquier actividad con la que los cristianos de al-Andalus se asociaron, ya fuera en la misma al-Andalus, o más tarde cuando habían emigrado a los reinos del norte peninsular. Hitchcock concluye afirmando que este término no puede ser empleado para designar a los cristianos que vivían en el territorio de al-Andalus. HITCHCOCK, R.: Mozarabs in Medieval and Early Modern Spain, Identities and Influences, Aldershot: Ashgate, 2008, págs. 10 y 150. 
la incorporación a la Dar al-Islam, que progresivamente fue perdiendo miembros hasta desaparecer en el último tercio del s. IX inicios del $\mathrm{X}$, aunque pensamos que escasamente arabizados. Expresamos esta opinión, porque los cristianos que convivieron con el poder establecido a partir del 30 de junio del 713, no tenían nada que ver con dicho término, y los que quedaron con posterioridad, somos de la opinión de que no les dio tiempo a «arabizarse» en el sentido cultural de la palabra, principalmente porque el desarrollo de los acontecimientos que tuvieron lugar en la ciudad y buena parte de su territorio no les fue propicio ${ }^{17}$.

Se ha discutido y publicado profusamente acerca de la existencia de una importante comunidad cristiana en territorio emeritense a lo largo de buena parte del periodo andalusí, cuando en realidad tanto el registro textual de la época, como el material conservado, ha ido desmontando esta falsa idea. Idea preconcebida que se ha mantenido a lo largo de los últimos años gracias a los cronicones redactados en los siglos XIV-XVI ${ }^{18}$, en un intento por recuperar el pasado esplendor de la iglesia emeritense, y así llevarlo hasta casi el momento mismo de la conquista de la ciudad por el rey leonés Alfonso IX ${ }^{19}$.

La documentación escrita que ha llegado hasta nuestros días acerca de la presencia cristiana en la Mérida andalusí, hace referencia únicamente a la pervivencia de la sede arzobispal hasta la segunda mitad del siglo IX d.C./III H, unos ciento cincuenta años con posterioridad a la presencia islámica en la ciudad. Esto en cuanto al medio urbano, porque el medio rural permanece bastante más críptico en cuanto a documentación textual se refiere. Bien es cierto que algunos edificios religiosos de la última fase del reino visigodo permanecieron abiertos al culto

17 En opinión de Miquel de Epalza «hubo muy pocos mozárabes en al-Andalus y muchos de los cristianos que aparecen en las fuentes son neo-mozárabes. La razón fundamental esgrimida es que, en al-Andalus hubo muy pocas posibilidades de que se mantuvieran comunidades cristianas constituidas, como las hubo en Oriente Medio (y por eso quedan hasta nuestros días cristianos árabes). En cambio, por esa misma dificultad en constituirse en comunidades cristianas o autóctonas, desaparecieron los florecientes obispados cristianos del Magreb, en fechas muy tempranas de la instalación del Islam en el N. de África» ibidem, 1985-86, pág. 174.

18 El historiador de Mérida Moreno de Vargas narra en su obra citas de cronicones antiguos, que no se corresponden en absoluto con los sucesos acaecidos en Mérida tras el 875/265, recogidos al unísono por la historiografía árabe, del mismo modo que el registro arqueológico se está encargando de confirmar. Hechos que resultan del todo improbables en una ciudad castigada por el poder cordobés y abandonada por las comunidades muladí y cristiana, que será tomada a continuación por los bereberes: Así «En tiempo de (Alfonso III), hay mención de Andrés, arzobispo de Mérida, que habemos de entender fue sucesor de Lando, porque el arcipreste Julián Pérez (in Cronicón an. 910. $n^{\circ}$. 465), dice que en el año de 910 entró Blassio en la iglesia de Toledo, y que celebró allí concilio, en que se hallaron Egas, obispo de Valencia; Andrés, de Mérida... y otros tantos treinta obispos» (MORENO DE VARGAS, B. Historia de la Ciudad de Mérida, Madrid, 1633, 8aㅡ reed. 1992: 343-44). De todos es conocido que no se celebraban concilios eclesiásticos por la comunidad cristiana de al-Andalus sin el consentimiento del emir, ni elección de obispos sin la soberanía del Estado, viniendo en esto a continuar con lo practicado por la monarquía visigoda, en LÓPEZ PITA, P. «Algunas consideraciones sobre la legislación musulmana concernientes a los mozárabes» Espacio, Tiempo y Forma, Serie III, H. ${ }^{a}$ Medieval, T. XX, UNED, Madrid, 2007, págs.163-181).

19 SIMONET, F. J. Historia de los mozárabes de España, deducida de los mejores y más auténticos testimonios de los escritores cristianos y árabes, IV Volúmenes, Madrid, 1903, reed. 1983, II, págs. 306 y ss. 
hasta su definitivo abandono ${ }^{20}$, seguramente durante las convulsiones que asolaron la ciudad a lo largo del siglo IX, si no fueron en algún caso convertidas en mezquitas o se arruinaron por falta de atención ${ }^{21}$. De igual modo se asiste al descubrimiento de restos materiales que indican que durante la fase inicial y central del emirato, se asentaron poblaciones cristianas en el medio rural, como medio de huir del centralismo cordobés y organizar comunidades cristianas en parajes alejados, buscando la seguridad que podían ofrecer algunas de las zonas más enriscadas y boscosas del territorio 22 .

Así en el desarrollo del presente artículo iremos desgranando la escasa documentación disponible, tanto la emanada de los textos como la del registro material, para adentrarnos en el conocimiento de la comunidad cristiana en la kūra de Mārida, la cual pervive, como iremos viendo, durante la primera fase del dominio islámico y a lo largo de la novena centuria, para desaparecer sin dejar rastro al final del citado siglo-inicios del siguiente. No obstante la documentación escrita deja entrever que parte de esta reducida comunidad cristiana emeritense se establecerá en el medio rural hasta su disolución, aunque mucho más dudoso es que se organizara entorno a un muy discutido Obispado con sede en Badajoz. Si bien es cierto que los datos que nos ofrece la cultura material para confirmar esta hipótesis, permanecen a fecha de hoy poco claros y confusos, debido principalmente a la insuficiencia de intervenciones arqueológicas que aporten nueva luz sobre esta problemática ${ }^{23}$. No así desde las fuentes textuales, que después de un detenido estudio realizado en los últimos años, han venido a demostrar que todo fue una argucia montada entre la iglesia y los círculos palatinos del monarca Alfonso $\mathrm{X}$ como medio de legitimar dicha sede, como avanzaremos más adelante.

\section{PERMANENCIA Y EVOLUCIÓN DE LA COMUNIDAD CRISTIANA DE MĀRIDA HASTA EL EMIRATO DE MUHAMMAD I}

Las fuentes historiográficas árabes no hacen mención de los edificios religiosos que se hallaban en Mérida en el momento de su rendición en el verano del

20 CAGIGAS, I. (de las) Minorías étnico-religiosas de la Edad Media Española. Los mozárabes (T. I-II), I.E.A., C.S.I.C. Madrid, 1947, pág. 58.

21 VALDÉS FERNÁNDEZ, F. «Arqueología islámica de Extremadura: los primeros cuatrocientos años», Extremadura Arqueológica IV, 1995, págs. 265-296.

22 CABALLERO ZOREDA, L. y SAÉZ LARA, F. La iglesia mozárabe de Santa Lucía del Trampal. Alcuéscar (Cáceres). Arqueología y Arquitectura, MArqEx, 2, Mérida, 1999. GIBELLO BRAVO, V. M. El poblamiento islámico en Extremadura. Territorio, asentamientos e itinerarios. Junta de Extremadura, Mérida, 2007, págs. 325-26.

${ }^{23}$ Problemática que ha sido estudiada desde dos ópticas por los siguientes autores: CRUZ VILLALÓN, M. ‥ «Badajoz visigodo, Badajoz mozárabe», Anas-7-8, Mérida, 1994-95, págs. $327-342$ y VALDÉS FERNÁNDEZ, F. «Acerca de la islamización de Extremadura». Cuadernos Emeritenses, n. 17, MNAR, Mérida, págs. 335-368. Del mismo autor: «La amarga claudicación. Los spolia del Alcázar Marwaní de Badajoz», Thomas G. Schattner y Fernando Valdés (eds.) en Spolia en el entorno del poder, Actas coloquio celebrado en Toledo del 21 al 22 de Sept. 2006, Iberia Archaeologica, 12, D.A.I, Madrid, 2009 , 469-488, págs. $472-474$ 
año 713 d.C./ 94h, ni de la comunidad cristiana que decidió permanecer en su solar. Sí resaltan en cambio, la riqueza de sus iglesias, que en gran medida pasaron a manos de los nuevos dominadores de la ciudad. Así se describe en el momento de su capitulación en una fuente anónima del siglo $\mathrm{XI}^{24}$ :

«...Confió Muça la guarda de la ciudad [Isbiliya] a los judíos, y se dirigió a la ciudad de Mérida, donde residían algunos grandes señores de España, y que también tenía monumentos, un puente, alcázares é iglesias que exceden á toda ponderación».

No olvidemos la donación de objetos de lujo y la entrega de grandes sumas de trientes visigodos realizada por patronos, obispos y miembros de la propia monarquía visigoda, como símbolo de ofrenda y penitencia a la memoria de los mártires y santos locales. Recordemos el rico tesoro con que contaba la basílica de Santa Eulalia de Mérida, incrementado sobremanera en la segunda mitad del siglo VI y primer tercio del siglo VII, por los obispos metropolitanos Pablo, Fidel y Masona ${ }^{25}$ Aunque esta riqueza habría llegado sin duda menguada a los inicios del siglo VIII, todavía sería lo suficientemente importante como para llamar la atención de los dirigentes musulmanes que tomaron la ciudad ${ }^{26}$. Bienes muebles y suntuarios que en el verano del 713 d.C./ $94 \mathrm{~h}$ fueron entregados al gobernador del Norte de África y conquistador de la ciudad, Mūsà ibn Nușayr, una vez se hubo pactado su rendición.

«...Ajustaron, en efecto, la paz, a condición de que los bienes de los que habian muerto el día de la emboscada, y los de aquellos que habian huido a Galicia, fuesen para los muslimes, y los bienes y alhajas de las iglesias para Muça;... ${ }^{27}$.

En este último punto, las fuentes historiográficas árabes hacen referencia expresa del cuantioso botín atesorado por la metrópolis lusitana, que fuera entregado personalmente a Mūsà, y del que tuvo que dar rendida cuenta al califa de Damasco 'Abd al-Malik, a su vuelta de la conquista del reino visigodo.

«...el jacinto de Dū l-Qarnayn, del que también se dice que es el que halló Mūsà ibn Nușayr en Mérida con la jarrita... Mūsa ibn Nușayr encontró el jacinto-además de la jarrita - en la iglesia de Mérida, que era iluminada por su resplandor» ${ }^{28}$.

24 'Ajbār Maŷmu'a, 1984, pág. 29.

${ }^{25}$ FRANCO MORENO, B. «La iglesia lusitana en la implantación del cristianismo trinitario en la Hispania romana y visigoda (Siglos III-VII d.C.)", Eúphoros. Revista del Centro Asociado de la UNED en el Campo de Gibraltar (Algeciras), № 6, 2004, págs.169-188.

${ }^{26}$ GARCÍA IGLESIAS, L. "Las posesiones de la iglesia emeritense en época visigoda» Estudios sobre la antigüedad en Homenaje al Profesor Santiago Montero Díaz, Gerión, Anejos II, U.C.M., 1989, págs. 391-401.

27 'Ajbār Maŷmu'a, 1984, pág. 30.

${ }^{28}$ Fath al-Andalus, (la conquista de al-Andalus), trad. Panelas Ruiz, M. Madrid, 2002, pág. 28. 
De igual modo, el gran cronista al servicio de la dinastía omeya, Ahmad al Rāzī, narra el relato de un ermitaño que describe una piedra que brillaba en las noches oscuras, como si fuera pleno día y donde se podían leer las oraciones sin necesidad de lámpara, relatando también como esta piedra se la llevó el líder árabe cuando entró en Mérida, junto a un vaso tallado en un bloque de piedra preciosa. Se dice que dicho vaso fue colocado en la mezquita de Damasco por el califa Sulaymān ibn 'Abd al-Malik ${ }^{29}$.

Abundan estos relatos en la historiografía musulmana, que vienen a mostrarnos la riqueza acumulada por la iglesia emeritense en el momento de la dominación islámica de la ciudad. Noticias que presuponemos no son nada descabelladas, teniendo en cuenta el pasado de la ciudad en la tardoantigüedad - recordemos su rango de capitalidad de la diócesis hispaniarum y sede regia temporal durante época visigoda-, cuando su iglesia se erigió en la más floreciente del periodo en la península ibérica [2. ${ }^{a}$ mitad del siglo VI, primer tercio del VII).

Ahora bien, de lo que no tenemos constancia por las crónicas árabes es a qué iglesias en concreto se refieren estas noticias. Sin duda tendrían que ser las más significativas de la ciudad y de toda la diócesis lusitana, y éstas no debían ser otras, que la Eclessia senior de Santa María de Iherusalem, situada intramuros, y la basílica de Santa Eulalia, extramuros.

Si tenemos en cuenta la influencia que durante toda la tardoantigüedad ejercieron los restos y reliquias de la mártir Eulalia depositados en la basílica emeritense, no sólo en la provincia lusitana, sino también en buena parte de la cristiandad altomedieval, no debería extrañarnos que la mayoría de estos ricos presentes se encontraran en el célebre santuario martirial, con sus tesoros, siempre objeto de codicia por otra parte, por los distintos pueblos bárbaros que pasaron por la ciudad y por algunos miembros de la iglesia cristiana unitaria arriana de finales del siglo $\mathrm{VI}^{30}$.

Tesoros litúrgicos y objetos de gran valor, material y simbólico, que se verían sustancialmente incrementados en el periodo inmediatamente anterior a la dominación islámica (2. ․ mitad del siglo VI-primer tercio del VII) como se pone de manifiesto en el Libro de las Vitas, cuando Masona dotó a la basílica de Santa Eulalia con más de dos mil sueldos de oro para socorrer a los más necesitados ${ }^{31}$. Cifra sin duda exagerada, pero que viene a mostrar la riqueza del complejo martirial, en

${ }^{29}$ AL-RĀZ̄̄, Catalán, D. y de Andrés, M. S., Crónica del Moro Rasis, Madrid, 1975, pág. 77.

30 CAMACHO, MACÍAS A, El libro de la vida de los Santos Padres de Mérida. Opúsculo anónimo del siglo VII, Estudio, texto latino, versión española, anotaciones y apéndices documentales, Mérida, (en sucesivo VPE) 2008: V. X-XI. ARCE MARTÍNEZ, J. «Augusta Emerita: continuidad y transformación (s. IV-VI)» Actas del Congreso Internacional 1910-2010 El Yacimiento Emeritense, Álvarez Martínez, J. Ma y Mateos Cruz, P. (eds.) Mérida, págs. 491-503.

31 VPE, 2008: V. III-8. 
una época donde la escasez del preciado metal era una realidad más que palpable para el común de los mortales.

Por otro lado hay que recordar, que aunque Toledo fuera elegida sede regia por la monarquía visigoda, el culto a la mártir no sufriría menoscabo alguno y seguiría plenamente vigente en buena parte de la península ibérica. Con respecto a la continuidad del culto durante la primera etapa del dominio islámico, tanto la iglesia de Santa María de Iherusalem, como la basílica de Santa Eulalia debieron de mantener su condición de templos cristianos a lo largo de todo el siglo VIII, como recogía la ley islámica en los tratados de capitulación que las tropas musulmanas acordaban con las dos religiones del Libro — cristianos y judíos - a la hora de llegar a acuerdos que beneficiaran a ambas comunidades ${ }^{32}$.

No eran estos los dos únicos edificios religiosos cristianos de Mérida que se mantuvieron en uso bajo el gobierno omeya de al-Andalus recogidos en las fuentes árabes. Isidro de las Cagigas señala que había cuatro iglesias más en esta situación con posterioridad al 713 d.C. $/ 94 h^{33}$, con una perdurabilidad que creemos alcanzaría hasta mediados del siglo IX. Estas serían las situadas extramuros, una dedicada a Sta. Lucía y otra a San Fausto, así como el xenodochium, en referencia al hospital próximo a la basílica de Santa Eulalia, y dos intramuros que podrían tratarse de San Andrés y Santiago ${ }^{34}$.

Otro de los aspectos que nos remiten a la raigambre y devoción profesada por el pueblo a la mártir Eulalia bajo el dominio musulmán, ya durante el siglo IX, lo tenemos en las reliquias conservadas en iglesias de Barcelona, Toledo y Córdoba $^{35}$. En esta última, capital del estado omeya de al-Andalus, San Eulogio trasmite la noticia que nos ha llegado a través del Calendario mozárabe de Córdoba redactado en el siglo $\mathrm{X}$, donde se conservaba una basílica consagrada a la advocación de la mártir y un sacrarium, ofreciéndosele también culto en la villa Careilas, situada en los alrededores de la ciudad ${ }^{36}$.

${ }^{32}$ Los musulmanes crearon para los dimmíes una legislación especial, que tuvo como base El Corán, la Sunna y los pactos o capitulaciones otorgados en el momento de la conquista.

${ }_{33}$ CAGIGAS, I. (de las) Minorías étnico-religiosas de la Edad Media Española. Los mozárabes (T. I-II), I.E.A., C.S.I.C. Madrid, 1947, pág. 58. ARCE MARTÍNEZ, J. «Augusta Emerita: continuidad y transformación (s. IV-VI)» Actas del Congreso Internacional 1910-2010 El Yacimiento Emeritense, Álvarez Martínez, J. M.ㄹ y Mateos Cruz, P. (eds.), Mérida, págs. 491-503.

${ }_{34}$ MATEOS CRUZ, P. «La identificación de Xenodochium fundado por Masona en Mérida» en IV Reunió d' Arqueologia Cristiana Hispánica. Lisboa, 1992. Monagrafies de la Secció Histórico-Arqueológica, IV. Barcelona, 1995, 309-316.

35 TORRES BALBÁS, L. «Mozarabías y juderías en las ciudades hispanomusulmanas», en Al-Andalus, 1954, Vol. XIX, 172-197. Toledo en una fecha tan avanzada como el siglo XI tenía su arzobispo, y se conservaban seis parroquias intramuros, que se mantuvieron abiertas al culto al parecer de manera ininterrumpida, hasta la conquista de la ciudad por Alfonso VI. Una de ellas era la dedicada a santa Olalla, que al parecer se hallaría próxima al centro de la madīna.

36 MANZANO MORENO, E. La expansión de los musulmanes en la península, Historia de España dirigida por John Lynch, Madrid, 2008, págs. 98-101. 


\section{ORGANIZACIÓN ECLESIÁSTICA Y EDIFICIOS MÁS REPRESENTATIVOS: IGLESIAS Y MONASTERIOS}

Tras la dominación islámica de la capital de la Lusitania, tanto las fuentes islámicas como las cristianas, no trasmiten noticia alguna acerca de la organización de la comunidad eclesiástica emeritense y de su conuentus jurídico. No obstante resulta lógico pensar, al igual que ocurre en buena parte del territorio andalusí, que durante el primer siglo de la historia de al-Andalus, la infraestructura y organización interna de la iglesia seguiría su curso sin sobresaltos aparentes en todo el territorio. Por lo menos esto es lo que se percibe de las fuentes escritas conservadas $^{37}$. Esta situación empezaría a cambiar tras las primeras décadas del siglo IX, cuando el poder cordobés exige más tributos a los dimníes, y por tanto vean peligrar el status pactado en el momento de la conquista ${ }^{38}$. Tanto la documentación árabe conservada como la cristiana, recogen testimonios de las insurrecciones protagonizadas por la comunidad cristiana en las ciudades más importantes de época emiral, como Toledo, Córdoba o la misma Mérida, al constatar como se iban perdiendo las costumbres en el seno de la comunidad e ir perdiendo las prerrogativas firmadas en su día con los nuevos dominadores.

No obstante pensamos que estas circunstancias tampoco variarían en demasía la infraestructura en el seno de la iglesia. En la metrópolis emeritense se mantenía su metropolitano a la cabeza, como se recogen en varios documentos donde figura su firma ${ }^{39}$. Suponemos que la jerarquía principal de la iglesia seguiría más o menos siendo la misma, destacando entre los más importantes los de canónigos, archidiáconos y arciprestes, así como los sacerdotes encargados de las parroquias. El obispo era elegido por representantes cualificados de la comunidad cristiana de la diócesis, a veces asociados a obispos de diócesis vecinas, que sería en más de una ocasión en nuestro caso, el titular de Mérida, al no quedar representantes en los obispados de la antigua provincia de la Lusitania. Estos puestos tenían que verse posteriormente ratificados por la autoridad civil musulmana, cuya intervención en el nombramiento del arzobispo metropolitano (mațrān)

37 Corpus Scriptorum Muzarabicorum, ed. I. Gil Fernández, Manuales y Anejos de «Emerita», T. XXVIII, 2 Vols., CSIC, Madrid, 1973. De los textos conservados podemos afirmar que el eje en torno al cual se articulaba la comunidad cristiana de Mérida era la estructura eclesiástica y su jerarquía. En cuanto a la pervivencia de las sedes de la diócesis durante el periodo andalusí, el padre Flórez indica en su tomo XIV de la E. S. que algunos obispos, como el de Egitania, Coimbra o Lamego fijaron su residencia en Asturias, de lo que podemos deducir que al no existir magisterio sobre la jerarquía inferior de la iglesia y sus feligreses, dichas sedes no pervivirían (España Sagrada, Flórez, Tomo XIII. Iglesias sufragáneas de Mérida, 1766).

38 MANZANO MORENO, E. «La conquista del 711: transformaciones y pervivencias», en Caballero, L. y Mateos, P. (eds.): Visigodos y Omeyas. Un debate entre la Antigüedad Tardía y la Alta Edad Media. Anejos de AEspA, XXIII, Madrid, 2000, págs. 401-414.

39 Flórez, E. España Sagrada, Tomo XIII, pág. 256; SANSÓN, Abad, Apologético, Lib. II, praefatio, n.ำ VIII. Edic. est. y trad. Palacios Royán, J. Madrid, 1998. 
resultaba de una mayor entidad ${ }^{40}$. La jerarquía eclesiástica en la Córdoba y Sevilla de periodo omeya, al igual que otros ejemplos del territorio andalusí, se encargarían de velar por el cumplimiento de la fe y de la conservación y reparación de los edificios cultuales, no sólo en la urbe, sino también en el medio rural. No obstante, en este aspecto no existe documento alguno que venga a ratificar esta aseveración para Mérida y su territorio a lo largo de todo el periodo descrito.

También debemos suponer en base a algunos documentos que se han conservado, que la comunidad cristiana en Mérida debía ser apreciable, aunque no comparable a la cordobesa, sevillana o toledana, que mantuvieron sus metrópolis operativas hasta bien entrado el siglo $\mathrm{XI}^{41}$. En Mérida por las circunstancias ya conocidas, la comunidad cristiana fue decreciendo paulatinamente, hasta desaparecer durante la segunda mitad del siglo IX, no manteniendo por tanto una existencia canónica real.

En cuanto a la información que nos suministra el trabajo arqueológico practicado en Mérida en las últimas décadas, viene a ratificarse lo ya mencionado en las fuentes escritas. Como es conocido por la mayoría en relación a la basílica de Santa Eulalia, las excavaciones arqueológicas desarrolladas a principios de la década de los noventa del pasado siglo, indican que permanecería abierta al culto hasta mediados del siglo IX, momento en el que se inicia su abandono y ruina ${ }^{42}$.

Respecto a otros edificios de carácter religioso repartidos por la ciudad, el registro material únicamente nos ha desvelado una posible basílica situada intramuros que relacionamos con San Andrés, ubicada tras el estudio realizado por su excavador, en el actual recinto del antiguo convento de Santo Domingo ${ }^{43}$. Para el medio rural hemos asistido al estudio y catalogación de algunos ejemplos significativos en los últimos años, que revelan la presencia cristiana en algún momento del periodo emiral ${ }^{44}$.

Así el mejor ejemplo estudiado lo tenemos en la basílica de Santa Lucía del Trampal, en la localidad cacereña de Alcuéscar, donde en las inmediaciones a un edificio cultual anterior se va congregar una pequeña comunidad cristiana en al-

40 VALENCIA RODRÍGUEZ, R. Sevilla musulmana hasta la caída del califato. Contribución a su estudio. Colecc. Tesis doctorales, U.C.M., Madrid, 1988, pág. 761.

41 Ibidem, pág. 760.

42 MATEOS CRUZ, P. y ALBA CALZADO, M. «De Emerita Augusta a Marida», en Caballero, L. y Mateos, P. (eds.): Visigodos y Omeya. Un debate entre la Antigüedad Tardía y la Alta Edad Media, Anejos de AEspA, XXIII, Madrid, 2000, pág. 156; MATEOS CRUZ, P. La basílica de Santa Eulalia de Mérida. Arqueología y urbanismo, Anejos de AEspA, XIX, Madrid, 1999.

43 FEIJOO MARTÍNEZ, S. Informe no 4002 de la Intervención efectuada entre los años 2003-2006 en la Plza. Sto. Domingo esquina c/ Oviedo: San Andrés. Dpto. de Documentación arqueológica del Consorcio Ciudad Monumental de Mérida.

44 Ejemplos recogidos en el Repertorio de Arquitectura Cristiana en Extremadura: Época Tardoantigua y Altomedieval, Mateos, P. y Caballero, L. (eds.), Anejos de AEspA, XXIX, Mérida, 2003, págs. 15-24 y 99-110 y CORDERO RUIZ, T. y FRANCO MORENO, B. «El territorio emeritense durante la Antigüedad Tardía y la Alta Edad Media», Caballero, L., Mateos, P. y Cordero, T. (eds.) Visigodos y Omeyas. El territorio, Anejos de AEspA LXI, Mérida, 2012, 147-169, pág. 158. 
gún momento del siglo VIII-IX. Su excavador, Luís Caballero, en base a la documentación obtenida fija su construcción durante el periodo emiral omeya ${ }^{45}$. Como hemos expuesto más arriba, se ubica en las proximidades de un edificio cultual de época romana, hecho que no excluye la edificación de un edificio de nueva planta siguiendo las novedades técnicas y arquitectónicas importadas de oriente (fig. 1).

Este edificio o complejo cultual más amplio, no estaba aislado, en sus proximidades se encontraba la iglesia de Santiago, entre cuyas ruinas han aparecido mármoles similares a los que tuvo Santa Lucía. Pero además, en las excavaciones han aparecido también restos de otros edificios que la rodeaban. A su lado Oeste había un edificio con su misma orientación y similares dimensiones. Otro edificio más pequeño se situaba junto a su esquina Noroeste. En cuanto a su ubicación, se encuentra en un lugar privilegiado, no muy alejado de la Vía de la Plata, con recursos hidráulicos y mineros que servirían de sustento para la comunidad cristiana asentada en sus proximidades. Al parecer, según se desprende de la excavación y del estudio de los materiales, su abandono tiene lugar al final del siglo IX-inicios del X, motivado con toda probabilidad por las mismas circunstancias que asolaron los edificios y la propia comunidad cristiana de la antigua metrópolis.

Otro ejemplo de presencia cristiana en el medio rural emeritense se encontraría sobre el punto más elevado de la Sierra de San Pedro, el denominado Torrico, perteneciente al término municipal de Salorino. Ubicado en torno a los $700 \mathrm{~m}$ de altitud, en una comarca que se caracteriza por su aislamiento y fragosidad boscosa, como medio de escapar a la fiscalidad y al control administrativo.

Así, pese a que echamos en falta una intervención arqueológica, nos encontramos con un poblado fortificado que utiliza buena parte de los afloramientos rocosos para su amurallamiento. Hallamos también en el mismo lugar la cimentación de un edificio que presenta una sencilla construcción de planta rectangular de unos $10 \mathrm{~m}$ de longitud por cinco de anchura, con disposición E-O (fig. 2). A poniente se le adosa una construcción menor de tres $\mathrm{m}$ de longitud por dos de ancho, mientras que hacia el este ofrece un muro semicircular. El edificio se hallaba construido en mampostería cuarcítica y cal, y se interpreta como una iglesia dotada de testero semicircular, nave y torre con campanario a los pies. También se encuentra abundante teja curva que nos informa de la cubierta que debió tener el edificio en su día ${ }^{46}$.

Este edificio se puede fechar por la cultura material perceptible en superficie, a una fase inicial del periodo emiral, momento en el que grupos de cristianos no islamizados dispersos en el territorio administrativo maridí, buscarían refugio en un emplazamiento inhóspito, dotado de defensas naturales capaces de proteger a

45 CABALLERO ZOREDA, L. y SAÉZ LARA, F. La iglesia mozárabe de Santa Lucía del Trampal. Alcuéscar (Cáceres). Arqueología y Arquitectura, MArqEx, 2, Mérida, 1999.

46 GIBELLO BRAVO, V. M. El poblamiento islámico en Extremadura. Territorio, asentamientos e itinerarios. Junta de Extremadura, Mérida, 2007, págs. 325-26. 
sus moradores, sin tener que disponer de complejos y onerosos sistemas constructivos.

Como indica Victor Gibello, la presencia de un edificio cristiano en un sitio tan aislado e inhóspito, sólo puede entenderse como el sostenimiento de la religiosidad por grupos humanos no receptivos a los procesos de cambio religioso y cultual como eran los que se estaban desarrollando en al-Andalus a lo largo del IX.

\section{LA COMUNIDAD CRISTIANA DE MĀRIDA HACIA SU DECLIVE EN LA SEGUNDA MITAD DEL SIGLO IX.}

Será con el progresivo afianzamiento de la política centralista marcada por la corte cordobesa, especialmente bajo los emires 'Abd al-Raḥmān ibn Al-Hakām y su sucesor Muhammad ibn 'Abd al-Raḥmān, a mediados del siglo IX, el que motivaría una sucesión de rebeliones encabezadas por la mayoría de los grandes propietarios y artesanos de Mérida, en las cuales no se acusan componentes predominantes de tipo religioso, sino más bien económico, que desencadenará el abandono de los edificios cristianos de la ciudad ${ }^{47}$. De este modo se entiende cómo la basílica de santa Eulalia, y su prestigio como lugar de culto y peregrinación, fue menguando según iba disminuyendo el número de creyentes, los cuales se irían convirtiendo paulatinamente al credo islámico, los recogidos en las fuentes como muwalladūm.

Será en estos cruciales momentos, como ya indicamos en el apartado de fuentes, cuando, por la célebre carta escrita en 826 por el emperador Ludovico Pío a los habitantes de Mérida, dirigida especialmente a su comunidad cristiana, tengamos otra vez noticias acerca de su situación ${ }^{48}$. En la misma se exhortaba a los emeritenses a resistir ante las acometidas del poder central, especialmente ante los fuertes tributos exigidos, de lo que deducimos pérdida de libertad respecto a la que habrían poseído hasta ese momento. También les ofrecía tierras en sus dominios por si deseaban abandonar al-Andalus.

Esta situación desembocaría, como ya conocemos no sólo por las fuentes, sino también por el registro material, en la toma de la ciudad por el emir 'Abd alRaḥmān ibn Al-Hakām y la construcción de la alcazaba, para de este modo controlar a la población y ubicar a los gobernadores nombrados al efecto desde Córdoba.

47 ALBA, M; FEIJOO, S. y FRANCO, B. «Mérida islámica (S. VIII-IX): El proceso de transformación de la ciudad tardoantigua en una medina» Xelb, 9 Actas do $6^{\circ}$ Encontro de Arqueología do Algarbe o Gharb no al-Andalus: sinteses e perspectives de estudo. Homenagem a José Luis de Matos (Silves, 23, 24 e 25 Octubro 2008), Silves, págs. 191-228.

48 FLÓREZ, E. España Sagrada, T. XIII. De La Lusitania en común y de su metrópoli en particular, 2. Edic. Madrid, 1816, Cap. IX, págs. 254-55. 
Esta decisión resultaría trascendental para el urbanismo de la madina, puesto que no sólo se amortizaron tramos de muralla para la edificación del recinto defensivo, sino que motivaría la destrucción de algunos de los más significativos templos cristianos que quedaban en la ciudad, como la arqueología ha puesto de manifiesto en los últimos años ${ }^{49}$. Así para la construcción del edificio del aljibe de la Alcazaba, se reutilizaron una serie de pilastras decorativas visigodas que son idénticas a las halladas en la excavación del complejo iglesia-hospital del Xenodochium, documentada por Pedro Mateos en el transcurso del año $1989^{50}$. De igual modo una inscripción funeraria dedicada al obispo Fidel fue hallada en las inmediaciones de la alcazaba, como material de acarreo para su construcción, circunstancia que nos lleva a pensar que incluso el área funeraria, que se situaría extramuros próxima a la basílica de Santa Eulalia, fue utilizada como cantera para la remodelación urbana acometida tras los sucesos del año 835/22051.

Estos sucesos desembocarían en el paulatino abandono de la ciudad por la comunidad cristiana, la cual se dirigiría hacia otros centros urbanos de al-Andalus y el noroeste cristiano (el reino astur), así como el establecimiento en parajes rurales como medio de escapar al control estatal. Muestra de lo expuesto son, como ya hemos mencionado, los restos constructivos y arquitectónicos de Santa Lucía del Trampal, basílica rural asociada a un complejo monástico más amplio, y el edificio de planta basilical ubicado en lo más alto del Torrico de San Pedro.

No volvemos a tener noticias acerca de la comunidad cristiana de Mérida hasta la celebración de un concilio en el año 839, celebrado en la capital del emirato para hacer frente a la herejía de los acéfalos. Al mismo asistieron los tres arzobispos más importantes de la iglesia del momento, los pertenecientes a las metrópolis de Toledo, Sevilla y Mérida, junto a otros cinco obispos y miembros menores del clero. Por medio de una carta, conocemos que el obispo metropolitano de Mārida en esta fecha se llamaba Ariulfo, por tanto resulta lógico pensar que la sede se mantuvo operante desde la época de la presencia islámica, hasta como mínimo la celebración de este concilio ${ }^{52}$.

Este mismo obispo figura al parecer en un concilio celebrado en Córdoba durante el año 852, con motivo de la problemática de los «mártires cordobeses», así como en uno nuevo celebrado más tarde en el año 862. A este último no pudo comparecer en persona el metropolitano de Mérida, aunque sí lo ratificaría por una carta enviada en ese mismo año al abad Sansón de Córdoba. En la misma le

${ }^{49}$ Bien recogido en MATEOS CRUZ, P. y ALBA CALZADO, M., "De Emerita Augusta a Marida», Caballero, L. y Mateos, P. (eds.), Visigodos y Omeyas. Un debate entre la Antigüedad tardía y la Alta Edad Media, Anejos de AespA XXIII, Madrid, 2000, págs. 143-168. MATEOS CRUZ, P. La basílica de Santa Eulalia de Mérida. Arqueología y urbanismo. Anejos de AEspA, XIX, Madrid, 1999, pág. 201.

${ }^{50}$ Véase nota 33

51 RAMÍREZ SÁDABA, J. L. y MATEOS CRUZ, P. Corpus de inscripciones cristianas emeritenses, Cuadernos Emeritenses, 16, M.N.A.R., Mérida 1999, págs. 71-72.

${ }^{52}$ FLÓREZ, E. España Sagrada, T. XIII. De La Lusitania en común y de su metrópoli en particular, 2. ${ }^{a}$ Edic. Madrid, 1816, Cap. XV, págs. 275-276. 
ofrecía todo el apoyo de la diócesis emeritense a favor del citado abad, contra la causa abierta por el obispo Hostégesis de Málaga, que lo quería apartar de la iglesia culpándole de hereje, en su afán por alcanzar encumbramiento y riqueza personal, aun a costa de olvidar a sus hermanos de religión ${ }^{53}$.

Tras este acto de seguimiento de la ortodoxia cristiana y de cumplimiento de las sagradas escrituras, mostrado por el más alto representante de la iglesia emeritense con el abad cordobés, no volveremos a tener noticia alguna sobre la diócesis emeritense, ni sobre sus obispos y fieles. Todo indica que tras los sucesos que tuvieron lugar en la ciudad en el año 868/254 y años sucesivos, la comunidad cristiana de la ciudad se vio en la obligación de abandonarla.

En este sentido compartimos la opinión manifestada por Mikel de Epalza al subrayar la total inoperancia que viviría la comunidad cristiana durante el periodo andalusí cuando faltara su más alto representante ${ }^{54}$. Y esto es, en efecto, lo que ocurrió con la comunidad cristiana de Mérida a final del siglo IX: que el éxodo de sus más altos representantes acabaría en pocos años con el otrora floreciente obispado emeritense. Ahora bien, según algunos testimonios escritos conservados, hablan de la presencia de miembros de esta comunidad en la vecina madīna de Badajoz, que junto a los rebeldes muladíes se establecieron conjuntamente tras pactar con el emir Muhammad I a partir del año 875/276. Incluso se ha afirmado que la ya reducida comunidad cristiana de Mérida crearía un nuevo obispado con el consentimiento de los Yilliqíes a principios del siglo X. Sin duda la creación de un nuevo obispado en una madīna de reciente fundación, sería un hecho único en la historia de al-Andalus, que como recogen todavía hoy día algunos autores, si llegó a materializarse fue debido al abandono de la sede emeritense y el apoyo con el que contó en Badajoz ${ }^{55}$.

Testimonio al que se aferra la iglesia aún hoy día, pero que después del exhaustivo trabajo desarrollado por Manuel Terrón Albarrán en la publicación conjunta sobre la Catedral de Badajoz, donde expone detalladamente los añadidos que han sufrido manuscritos y legajos para justificar la sede pacense para dotarla de raigambre y pasado frente a la de Beja, ha quedado resuelto que durante todo el periodo andalusí esta nunca existió.

Como describe Terrón Albarrán en su artículo, hacia el año 903-904, el día después de la expedición de Ordoño II a Badajoz, sale de la ciudad un obispo que

${ }^{53}$ El obispo de Málaga, Hostegesius, consiguió que se condenase por herejía al célebre abad Sansón, de manera tan injusta que la mayoría de los obispos presentes, que consintieron la condena, se fueron desdiciendo después por escrito o de palabra, y el abad cordobés pudo así ver restituido su honor y ser nombrado rector de la iglesia de san Zoilo (Abad Sansón, Apologético, 1998, pág. 75).

${ }^{54}$ EPALZA, M. (de) «La Islamización de al-Andalus: Mozárabes y neomozárabes», Revista del Instituto Egipcio de Estudio Islámicos, XXIII, Madrid, 1985-86, págs. 171-179; del mismo autor: «Falta de obispos y conversión al Islam de los cristianos de al-Andalus", Al-Qanțara, 15-II, 1994, págs. 385-399.

55 LÓPEZ LÓPEZ, T. A. «La Iglesia mozárabe del Badajoz Islámico» en Actas del XXX Coloquios Históricos de Extremadura, Trujillo 24-30 sept. 2001, 2001, 325-356, pág. 332. 
firma cartas con el nombre de Theudecutus, Baiciense sedis episcopus. No obstante Terrón Albarrán niega con toda la razón que este obispo abandonara la ciudad, puesto que no había motivo en ese momento para ello ${ }^{56}$. Este mismo autor demuestra tras un exhaustivo estudio de los manuscritos, que este obispo en todo caso era titular de la sede de Baza ${ }^{57}$. En cambio sí se ha mantenido como más fiable la presencia del obispo Julius hacia el 930 por un documento conservado del año 932, tras la implantación del Califato en al-Andalus, donde firmaba al parecer como episcopus de Badaliaucu, aunque esta es una cuestión que no está del todo clara entre la comunidad científica. En todo caso esta titularidad resultaría más áulica que canónica ${ }^{58}$.

Como hemos expuesto en nuestro trabajo sobre la kūra de Mārida, para este fase final del emirato, creemos que Badajoz no capitalizaría provincia propia, pudiendo en todo caso depender de la kūra de Mārida, aunque sólo fuera nominalmente ante el debilitamiento que sufre la administración omeya durante el mandato del emir 'Abd Allah ${ }^{59}$. Tal vez por este motivo se ha creído en la existencia de este nuevo obispado, que de todos modos tras consultar las fuentes árabes, parece del todo improbable, sobre todo porque no creemos que el citado emir permitiese en los últimos años del emirato este alarde de proselitismo con la comunidad cristiana de al-Andalus ${ }^{60}$.

Así y después de consultar el mencionado estudio acerca del obispado «mozárabe" de Badajoz, Terrón Albarrán recoge cómo fue el padre Simonet el que ideó la traslación-creación de esta nueva sede, que contaría con el beneplácito de la dinastía muladí de los Yilliqies, además de dar como válido lo recogido en el Códice árabigo de $1049^{61}$. De igual modo viene a afirmar, que nada presupone un traslado de sede tras los acontecimientos vividos en la capital maridí y la posterior fundación de Badajoz, ante los vaivenes que sufrirá la recién creada madīna a lo largo del último tercio del siglo IX. También documenta, después de llevar a cabo una exhaustiva labor investigadora, que las noticias sobre los primeros prelados adscritos a la sede badajocense, durante el periodo Omeya de al-Andalus -Theudecutus (904-905?); Iulius (932) y Daniel (1000)— son un complejo tramado, urdido en el siglo XIII en el organigrama político del rey Alfonso X, como medio

\footnotetext{
56 TERRÓN ALBARRÁN, M. Extremadura musulmana (713-1248), Badajoz, 1991, pág. 248.

57 TERRÓN ALBARRÁN, M. «I. Petrvs Primvs Episcopvs Pacensis. Sobre los orígenes de la Catedral y Obispado de Badajoz: nuevas reflexiones y tanteos» en La Catedral de Badajoz (1255-2005), Badajoz, 2007, págs. 19-144.

58 Ibidem, pág. 72-75.

59 FRANCO MORENO, B. De Emerita a Mārida. El territorio (S. VII-X) Vol. Il. EAE, Saarbrücken (Germany), 2011, págs. 55-62.

${ }^{60}$ Es sobradamente conocido que la comunidad cristiana no podía hacer proselitismo de su religión, ni menos construir nuevos edificios religiosos dentro del espacio urbano, aunque sí mantenerlos en buen estado para que no se derrumbaran.

61 TERRÓN ALBARRÁN, M. «I. Petrvs Primvs Episcopvs Pacensis. Sobre los orígenes de la Catedral y Obispado de Badajoz: nuevas reflexiones y tanteos» en La Catedral de Badajoz (1255-2005), Badajoz, 2007, págs.19-144.
} 
de dotar de raigambre histórica a la iglesia de Badajoz en pro de sus aspiraciones, frente a la sede primigenia de Beja del país vecino ${ }^{62}$

En cuanto a las reliquias de los mártires conservadas en Mérida, sí todavía quedaban algunas, debieron ser trasladadas al reino Leonés al final del siglo IXinicios del $\mathrm{X}$, tras una incursión cristiana en territorio musulmán. Con toda probabilidad bajo el reinado de Alfonso III u Ordoño II, y no con anterioridad durante el reinado de Silo I, como a recogido la tradición ${ }^{63}$. Ya el historiador local Moreno de Vargas, hacía referencia en su Historia de la Ciudad de Mérida a esta falsedad documental, en su día recogida en el Chronicon Sebastiani y trasmitido posteriormente por Ambrosio de Morales ${ }^{64}$. No olvidemos que Silo I nunca realizó expedición alguna fuera de su reino, ya que bastante tuvo con conservar el poder en un periodo de claro empuje omeya. Más loable resultaría esta empresa cuando estallaran las revueltas de 'Abd al-Raḥmān ibn Marwān ibn Ŷunūs y la posterior fundación de Badajoz, que repobló con las comunidades muladí y algunos cristianos que abandonaron Mérida, en el momento propicio de su acercamiento con el rey Alfonso III. En todo caso el ejército de éste último se encargaría de transportar los escasos restos martiriales de la santa Eulalia de Mérida, que con toda seguridad habrían sido recogidos por los últimos fieles cristianos antes de abandonar la destruida y disminuida madīna tras los sucesos del año 868. En la actualidad, según recoge la tradición popular, las reliquias de la mártir se encuentran custodiadas en una capilla lateral de la catedral de Oviedo ${ }^{65}$.

A partir de este momento se pierde todo rastro de la comunidad cristiana de Mārida, no llegando hasta nuestros días documentación alguna que venga a afirmar lo contrario. Si las metrópolis de Córdoba, Toledo o Sevilla perviven hasta finales del siglo XI, entre otros motivos, por la pervivencia de sus comunidades de fieles y el nombramiento de sus Obispos, la sede emeritense se extinguió por la falta de sus más altos dignatarios y el exilio del resto de creyentes, como consecuencia de los acontecimientos que tuvieron lugar en la ciudad, y que a la postre significaría el definitivo declinar de la urbe en los planes administrativos de la dinastía omeya.

\section{CONCLUSIONES}

De lo expuesto podemos extraer brevemente, que la Comunidad cristiana de Mérida continúo integrada en su iglesia, con su obispo a la cabeza, tras la capitu-

62 Ibidem, págs. 101-118. Incluso en el seguimiento de este empeño se realizaron añadidos a documentos escritos en árabe, como medio de demostrar la antigüedad de la sede badajocense. Así viene recogido en el Código canónico árabe 593 de la Biblioteca Nacional (año 1049-1050) redactado por un clérigo cristiano afincado en Toledo a mediados del siglo XI (Baudrillart. Dictionnaire' d'Histoire et de Geógraphie ecclésiastiques, tomo VI, Baader- Baviere, París 1932, art. Lambert, pág. 100).

63 Crónicas Asturianas (Crónica de Alfonso III «Rotense y A Sebastían, Albeldense y profética»). Int. Edic. Crítica Juan Gil Fernández, trad. y notas José L. Moralejo y Ruíz de la Peña, Univ. Oviedo, 1985.

${ }^{64}$ MORENO DE VARGAS, B. Historia de la Ciudad de Mérida, 1633, 8aㅡ edición, 1992, págs. 167 y ss.

65 RICO-AVELLO, C. (1989) «Asturias y santa Eulalia de Mérida», Miscelánea Asturiana, Salinas, págs. 13-18. 
lación de la ciudad a las tropas capitaneadas por Musa ibn Nușayr en junio del año 713 d.C./ 94 H. Tras la firma de los acuerdos la comunidad cristiana se integraría de manera paulatina en la sociedad islámica, aunque no se ha conservado documento alguno que recoja su participación en los sucesos que tienen lugar en Mérida durante los primeros cincuenta años. Será a partir de la consolidación del estado omeya a finales del siglo VIII-inicios del IX cuando la comunidad cristiana participe en las revueltas que se suceden en Mérida, en un ambiente de intranquilidad y enfrentamiento ante los dictados que se emiten desde Córdoba. Pero serán muladíes y bereberes los que capitalicen tales enfrentamientos, aliándose la comunidad cristiana a unos u otros dependiendo de las circunstancias.

Las actas conservadas de los Concilios celebrados en al-Andalus de mediados del siglo IX, confirman la participación de la más alta jerarquía eclesiástica emeritense, constatado por la firma de su Obispo Ariulfo. Su adhesión a las tesis del Abad Sansón de Córdoba en contra del Obispo Hostégesis así lo confirman, llegándose así hasta los sucesos que tuvieron lugar en Mérida en el 868/254 donde las tropas encabezadas por el emir Muhammad tomaron la ciudad y arrasaron sus murallas, trasladando a Córdoba a los líderes de las revueltas encabezadas por la Comunidad muladí. Aunque la Comunidad cristiana de la ciudad no participó activamente en esta última revuelta, por lo menos no consta en registro textual alguno, sus miembros debieron huir de la ciudad y buscar refugio en el norte peninsular y en el medio rural. El registro material estudiado confirma la presencia de pequeñas comunidades cristianas en el medio rural, en torno a monasterios o pequeñas alquerías fortificadas, que permanecerán en activo hasta inicios del siglo $X$. En cuanto al medio urbano, el abandono de los pocos edificios cristianos que quedaban en la ciudad tras los sucesos mencionados, y el exilio de la comunidad cristiana de Mérida, mayoritariamente al territorio controlado por el reino asturleonés, hacen improbable la existencia de culto en la basílica más importante de la ciudad, la dedicada a Santa Eulalia. Este y otros edificios religiosos una vez abandonados se irían deteriorando durante el resto de la dominación islámica. El registro arqueológico practicado en la primera ha venido a confirmar finalmente que el edificio se encontraba en ruinas al final de la novena centuria. El mismo se reaprovechará como lugar de almacenamiento y para labores agropecuarias, al hallarse en su interior un pozo de noria.

No hay que olvidar que la ciudad había perdido gran parte de su población y de su anterior importancia en los nuevos planes políticos y administrativos de la corte cordobesa, perdiendo a su vez la sede metropolitana que no volverá a recuperar ni aún después de su conquista por las tropas encabezadas por Alfonso IX en 1230.

En cuanto al traslado de la sede emeritense en los inicios del siglo $X$, con sus miembros más destacados a la recién fundada madina de Badajoz, los estudios publicados en los últimos años vienen a esclarecer que dicha sede fue una estrategia tardía para legitimar las aspiraciones de la sede de Badajoz ante la de Pax Iulia (Beja) en una fecha avanzada como la segunda mitad del siglo XIII. 
Figuras.

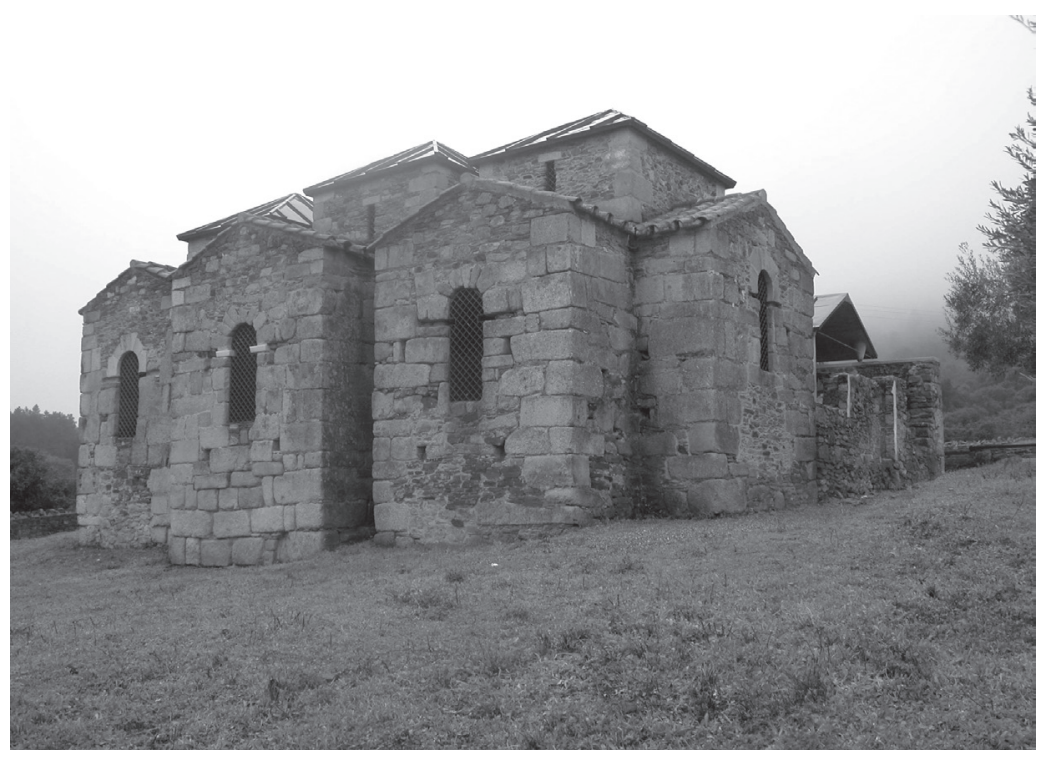

Fig. 1 Cabecera de la basilica «mozárabe» de Santa Lucía del Trampal (Alcuéscar, Cáceres) Foto. El autor.

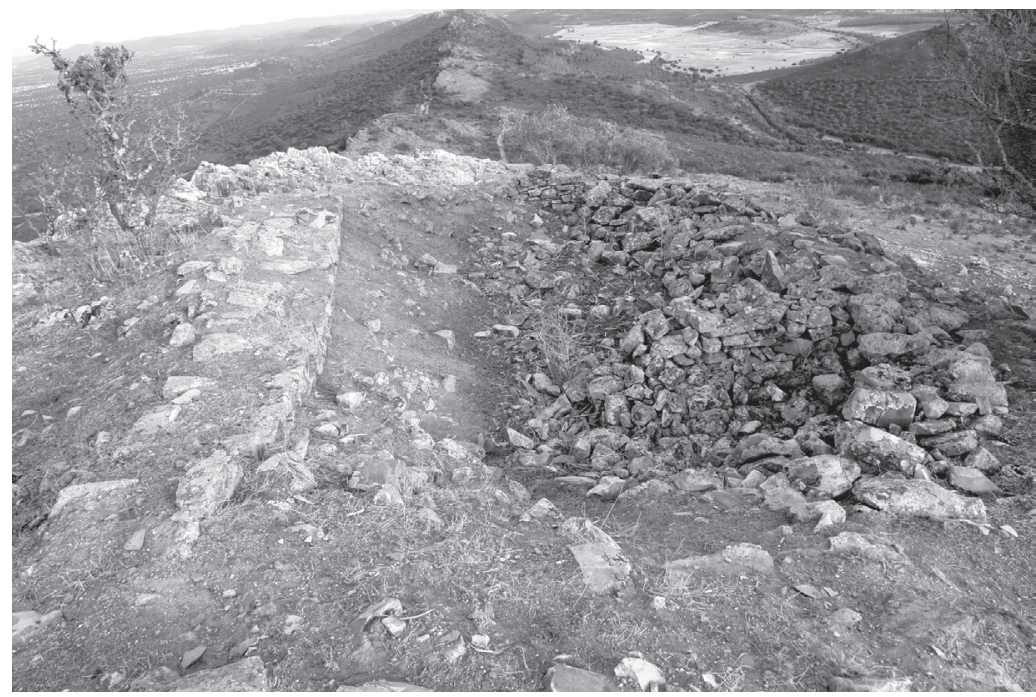

Fig. 2 Restos de cimentación del probable edificio religioso del Torrico de San Pedro (Salorino, Cáceres) Foto: Victor Gibello Bravo. 